\title{
A RETÓRICA DA VERDADE NO RELATO JORNALÍSTICO
}

\section{THE RHETORIC OF TRUTH IN THE JOURNALISTIC STORY}

Marco Antônio Gutierrez ${ }^{1}$

\section{Resumo}

Assumido pelos manuais de jornalismo como narrativa imparcial de fatos objetivos, o relato noticioso é, contudo, incapaz de esconder seus compromissos ideológicos com uma versão determinada dos eventos que narra. Analisando a retórica do texto verbal e das imagens associadas a um relato específico em três diferentes veículos de comunicação na Internet, o presente artigo procura refletir sobre a "objetividade" dos relatos jornalísticos, em particular, e sobre a "transparência" da linguagem em geral. Esta reflexão parte da vulgarização das idéias semânticas de Frege feita por alguns manuais de jornalismo e termina com uma análise sucinta sobre o uso ideológico dos esquemas imagéticos de container e força.

Palavras-chave: Retórica; relato jornalístico; metáfora.

\begin{abstract}
Manuals of journalism conceive news stories as impartial narratives of objectives facts. Nevertheless, they seem to be incapable of concealing their ideological commitments with a particular version of told facts. This article analyzes rhetorical organization of text and images within a specific story published by three different communication vehicles in the Internet. It tries to think about journalistic stories "objectivity" and about "transparency" of language in general. This reflection starts on vulgarization of Frege's semantic ideas made by some of those manuals and ends on a briefly analysis of ideological use of containment and force image schemas.
\end{abstract}

Keywords: Rhetoric; journalistic story; metaphor.

Em 16 de dezembro de 2005, durante a realização de reunião plenária da Organização Mundial do Comércio, um grupo de pessoas que realizavam manifestação de protesto relacionada ao evento nas suas imediações acabou por se ver em confronto com a polícia de Hong Kong, resultando em inúmeras prisões e vários feridos".

A questão de determinar quais as relações mantidas pelo relato do parágrafo anterior com um conjunto de eventos ocorridos numa certa cidade da China está longe de ser trivial. E mais: aquele pequeno relato não constitui o único possível de ser enunciado a cerca daqueles eventos. De fato, o incidente

\footnotetext{
${ }^{1}$ Mestre em Lingüística - UERJ. magut@ism.com.br
} 
foi testemunhado por vários correspondentes de diversas agências noticiosas, cujos relatos foram publicados em diferentes órgãos de imprensa em todo mundo. $\mathrm{Na}$ verdade, o relato proposto é inteiramente baseado em algumas dessas publicações: o relato publicado no portal Terra, o publicado no portal UOL e o publicado no portal Globo On-line, os primeiros baseados diretamente no despacho da agência EFE e o último, em vários despachos.

É notável nos vários relatos arrolados o fato de todos serem constituídos por proposições a propósito de um recorte da "realidade"; todos são compostos por sentenças assertivas a propósito de algum aspecto do mundo. Portanto, podemos pôr o seguinte problema: qual o referente das sentenças componentes dos relatos? Qual a relação entre o referente dessas sentenças e os fatos ocorridos em Hong Kong? Que relações os diferentes relatos mantêm entre si?

\section{Referente, relato, objetividade}

Comecemos por colocar o problema do ponto de vista da própria imprensa, tal como exposto por alguns manuais destinados aos próprios jornalistas. Para esses manuais, "o que se busca é a notícia: o fato comprovado, relevante e novo", pois "fatos são mais fortes do que declarações" (FOLHA DE SÃO PAULO, 2001, p. 27). Mais do que um relato, a notícia é vista como o próprio fato que relata. $\mathrm{E}$ para que isso seja possível, os manuais aconselham: "faça textos imparciais e objetivos. Não exponha opiniões, mas fatos, para que o leitor tire deles as próprias conclusões" (O ESTADO DE SÃO PAULO, 1990, p. 18). Tal programa só é alcançável se a linguagem na qual se baseiam os relatos jornalísticos for transparente, isto é, puder servir como "veículo" objetivo para os fatos narrados. Isto torna possível a proposta de que o jornalista seja um observador privilegiado dos fatos e seu mediador com o leitor. Ou, novamente no dizer desses manuais, "o jornalista funciona como intermediário entre o fato ou fonte de informação e o leitor" (FOLHA DE SÃO 
PAULO, 2001, p. 16). Esse programa se funda em alguns pressupostos básicos, a saber:

i Os fatos são objetivos, isto é, são os mesmos para todos os observadores;

ii A verdade está nos fatos e não nos relatos, que apenas a transmitem;

iii É possível utilizar a linguagem como um veículo transparente dos fatos.

Esses pressupostos estão notavelmente próximos da vulgarização das concepções da lógica clássica, tal como formulada por Frege. Para o filósofo, devemos assumir que todas as sentenças assertivas tenham um referente $\mathrm{e}$ que este referente seja a própria realidade. Ao discutir o problema da significação, Frege assinala que "um nome próprio (palavra, sinal, combinação de sinais, expressão) exprime seu sentido e designa ou refere-se à sua referência", entendendo por "referência" (do sinal) um objeto determinado, uma entidade "objetiva, na medida em que pode servir a vários observadores" (FREGE, 1978, p. 66), pré-existente à linguagem que o designa. O referente do sinal, o que é designado por ele, não é, portanto, o conceito, que é entendido como apenas o seu sentido.

Para esse enfoque, uma sentença como "Policiais e manifestantes enfrentam-se em Hong Kong", que legenda a foto publicada no portal Terra (ver Figura 1Erro! Fonte de referência não encontrada.), constitui-se num pensamento completo (expresso pelo sentido daqueles sinais) que designa determinados eventos ocorridos em Hong Kong. Tais eventos são objetivos, estão (ou pelo menos estavam no momento de sua ocorrência) disponíveis para qualquer observador. Portanto, para essa concepção a linguagem - ou pelo menos aquele subconjunto da linguagem composto por sentenças assertivas completas - lida com fatos passíveis de observação e não com conceitos ou pensamentos. Estes são apenas o sentido dessas sentenças. 


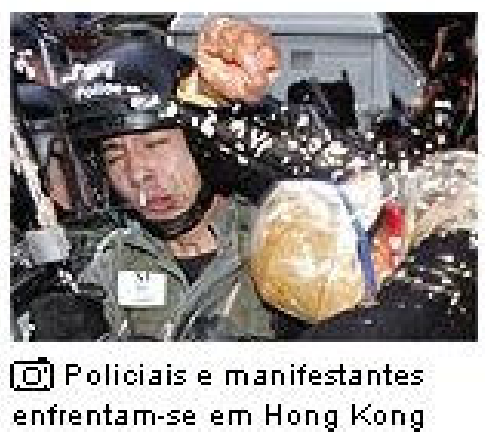

Figura 1: llustração do relato do Terra

Essa distinção é crítica para o pensamento de Frege porque o centro de suas preocupações está no valor de verdade das proposições e este deve estar no mundo, nos objetos, e não no pensamento. Frege entende que a verdade não é uma relação entre sujeito e predicado, já que estes são "partes do pensamento; eles estão no mesmo nível no que tange ao conhecimento" (FREGE, 1978, p. 70). Isto leva Frege a reconhecer que o valor de verdade de uma sentença é a sua referência. Numa concepção como essa, "os juízos podem ser encarados como uma trajetória de um pensamento para seu valor de verdade" (FREGE, 1978, p. 70). Em outras palavras, se na cidade da China conhecida por todos (no ocidente) como Hong Kong um grupo de pessoas investidas pelo estado com o poder de polícia e um outro grupo de pessoas que manifestavam sua oposição à reunião da OMC entraram em confronto, ambos como agentes desse confronto, em 16 de dezembro de 2005, se este fato observável ocorreu, podemos então emitir o juízo de que a sentença da Figura 1Erro! Fonte de referência não encontrada., "Policiais e manifestantes enfrentam-se em Hong Kong [em 16 de dezembro de 2005]" é verdadeira.

Mas a sentença da Figura 1 nos permite inferir mais do que simplesmente a união das proposições "policiais enfrentam manifestantes" e "manifestantes enfrentam policiais". Ela parece sugerir que ambas as partes atacaram a outra ao mesmo tempo, sem que se possa inferir a existência de um agressor inicial 
ao qual o outro simplesmente reagiu. No entanto, a fotografia diz algo que não está dito na legenda, possivelmente contraditando-a. Dentre as centenas de fotos disponíveis para captar o fato, os editores selecionaram uma delas - e talvez a única - onde é a polícia a ser agredida e não os manifestantes.

Nossa cultura está habituada a considerar a fotografia em geral, mas especialmente a jornalística, como um "instantâneo" da realidade. De um modo geral, consideramos que a realidade "é definida com base na correspondência entre a representação visual de um objeto e o que normalmente vemos deste objeto à vista desarmada" (KRESS \& VAN LEEUWEN, 1996, p. 163). Trata-se de uma definição "naturalizada" da realidade; ela é, contudo, fundada sobre a capacidade de resolução de cores e imagem da fotografia em 35 milímetros típica do cinema sob a tecnologia atual - e certamente não era a definição da pintura realista anterior à invenção da fotografia. Essa definição depende de um conjunto de fatores convencionais - perspectiva, diferenciação cromática, temas, etc. Em outras palavras, "a realidade está nos olhos do observador" (KRESS \& VAN LEEUWEN, 1996, p. 163). No entanto, estamos tão habituadas a essa definição que "esquecemos" seu caráter convencional e a assumimos como a própria "realidade" representada pela fotografia.

A fotografia é, pois, menos um instantâneo da realidade e mais um instantâneo do observador que a interpreta. Isto fica evidente na Figura 1Erro! Fonte de referência não encontrada.. Neste caso, o responsável pela publicação da fotografia se compromete com uma determinada interpretação dos eventos - aquela onde a polícia é agredida pelos manifestantes de Hong Kong. O interessante é que este compromisso não se observa na frase usada como legenda: ambos realizam enunciados distintos. No entanto, como o efeito de realidade da fotografia é maior que o da linguagem verbal, o compromisso com uma interpretação dos fatos passa despercebido, tomado pelo leitor desatento como a própria realidade. Em outras palavras, na fotografia do Terra, a combinação entre imagem e texto se utiliza de um artifício retórico destinado a convencer o leitor de uma interpretação dos eventos. 
Relações distintas entre imagem e texto são utilizadas na página do Globo (ver Figura 2); no entanto, elas conduzem a uma atitude geral diante dos eventos bastante próxima. A imagem aqui "fala" um discurso próximo à legenda do Terra, com policiais e manifestantes se enfrentando. No entanto, o texto assume imediatamente o compromisso carente na fotografia, quando assinala que "manifestantes entram em choque com a polícia". Essa sugestão é corroborada por outra sentença (elíptica) encontrada na mesma ilustração: "protesto e revide". Essa sentença não parece ser simplesmente uma conjunção de duas proposições simples. A escolha vocabular sugere que "protesto" é um ato agressivo, conferindo à sentença características de uma implicação lógica. Tudo se passa como se fotografia e texto, nos dois sites citados, fossem os enunciados de um argumento - o de que a polícia foi atacada pelos manifestantes e simplesmente reagiu.

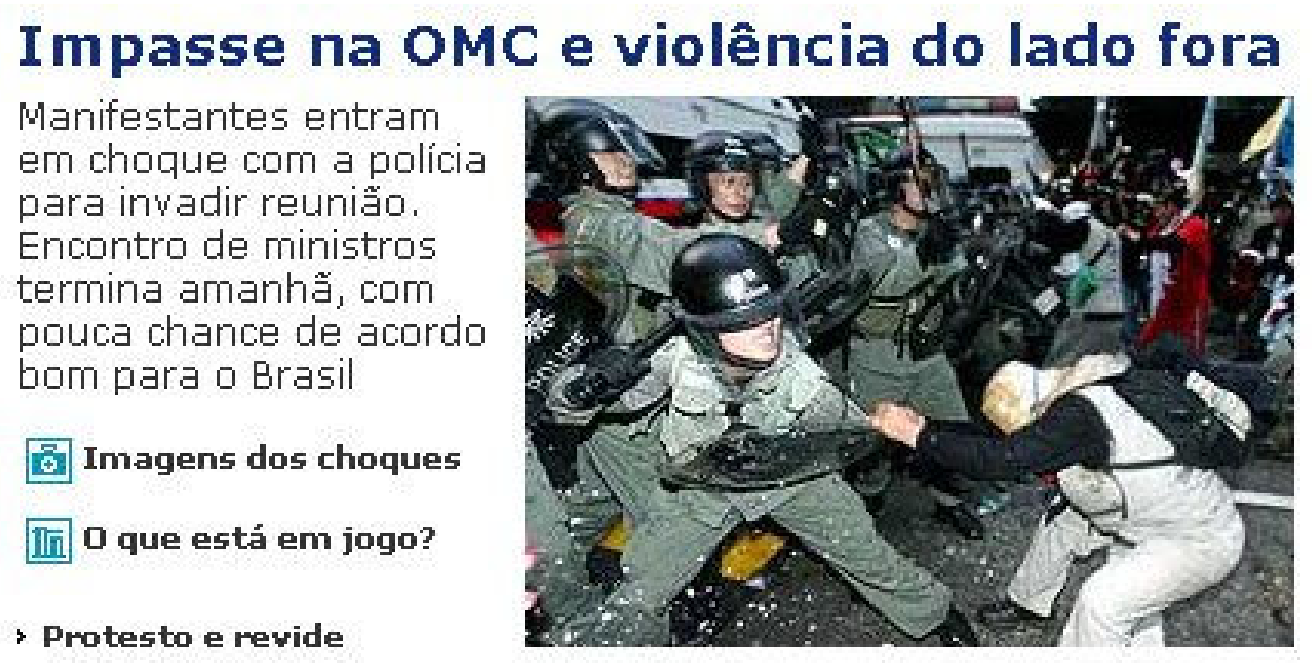

Figura 2: llustração do relato do Globo.

É fácil notar que os três relatos colhidos na Internet (mas não o "contrarelato" que construímos a partir deles) concordam numa atitude interpretativa básica, que corrobora $\mathrm{o}$ argumento expresso no parágrafo anterior: os manifestantes se "uniram para atacar" e, com isso, "romperam" a barreira policial; os "protestos (mas não a ação policial) foram violentos"; a polícia lutou 
apenas para "evitar a invasão". A Tabela 1, com extratos de todos os relatos, ilustra esse ponto.

\begin{tabular}{|l|l|l|}
\hline & Sentença & Fonte \\
\hline 1 & Um grupo de manifestantes conseguiu romper hoje o cerco policial & Terra \\
\hline 2 & os ativistas se uniram para atacar as barreiras policiais & Terra \\
\hline 3 & os violentos protestos ocorridos às portas do centro de convenções & UOL \\
\hline 4 & $\begin{array}{l}\text { forças de segurança lutavam para evitar a invasão do centro de } \\
\text { convenções por manifestantes }\end{array}$ & Globo \\
\hline
\end{tabular}

Tabela 1: Manifestantes atacam a polícia em Hong Kong.

Mas por que não é possível dizermos que essas "atitudes" não exprimem o que de fato ocorreu? Simplesmente porque podemos imaginar um conjunto de sentenças que afirme precisamente o contrário (isto é, podemos imaginar uma proposição que afirme que "os policiais atacaram os manifestantes") e, dados somente os relatos, não temos como emitir conclusivamente um juízo de verdade sobre suas proposições. Para a perspectiva que utilizamos como referência, o fato de todos os observadores citados concordarem implicitamente com a negação dessa proposição, não pode afetar seu valor de verdade. Lembremos que, para Frege (como também para os manuais jornalísticos), o valor de verdade de uma proposição está no referente e não no sentido; logo, podemos imaginar um conjunto de condições tais que todos os observadores concordem com uma proposição e ela, ainda assim, seja falsa! Aliás, é precisamente isso que inferimos a propósito da discussão fregeana sobre as expressões "estrela da manhã" e "estrela da tarde": até que os astrônomos "descobrissem" que seu referente era o mesmo e um planeta (e não uma estrela), todos os observadores concordavam com as proposições contrárias a essas!

A questão em jogo aqui envolve a noção fregeana de "observador" (neutro) e sua concepção implícita de "conhecimento como descoberta" (da verdade), concepção filosófica assumida e vulgarizada pelos manuais jornalísticos citados. Para que seja possível emitir um juízo, a "trajetória de um 
pensamento para seu valor de verdade" deve ser conduzida por um observador capaz olhar o referente "objetivamente", em si mesmo, independente das proposições através das quais o designamos. Nesse contexto, uma sentença verdadeira é uma sentença passível de ser enunciada por esse observador privilegiado, capaz de se libertar da "imperfeição da linguagem", capaz de se tornar o sujeito de uma "linguagem logicamente perfeita", onde cada sinal "designe, de fato, um objeto", onde "nenhum sinal seja introduzido como nome próprio sem que the seja assegurada uma referência" (FREGE, 1978, p. 76). Para esse sujeito ideal, observador neutro da "realidade", capaz de emitir juízos perfeitos sobre as proposições, o conhecimento é simples processo de descoberta de uma verdade que é propriedade das coisas e não do modo como compreendemos as coisas. Para esse Sujeito da Verdade, a linguagem precisa ser "um meio para alcançarmos uma verdade que está fora da linguagem, $O$ que nos permite falar objetivamente sobre 0 mundo $e$, conseqüentemente, adquirir um conhecimento seguro sobre ele" (OLIVEIRA, 2000, p. 27).

Mas suponhamos que eu me chame H.G. Wells, invente um dispositivo capaz de viajar no tempo (e no espaço) e me transporte para a Hong Kong de 16 de dezembro de 2005. Suponhamos também que eu me coloque em posição tal que me torne observador privilegiado daqueles eventos e, com isso, constate que, de fato, foi a polícia quem atacou os manifestantes e não o contrário. Com isso, eu enuncio a sentença referida anteriormente ("os policiais atacaram os manifestantes") e a incluo num relato publicado, digamos, pela hipotética Agência Green Peace de Notícias. Imaginemos agora que o leitor é o webmaster de um dos portais escolhidos para compor nosso corpus e precisa escolher quais dos relatos (contraditórios) utilizar na sua própria matéria. Como decidir qual das proposições é verdadeira? Em outras palavras, é possível emitir um juízo perfeito sobre os conhecimentos expressos nos vários relatos? A resposta da vertente de Frege seria, certamente, não, simplesmente porque o evento singular designado pelos relatos está inacessível - mesmo para um 
observador neutro. Se tudo o que temos à disposição é a linguagem utilizada para designar o objeto, não é possível emitir esse juízo perfeito - mesmo no quadro das concepções fregeanas. Com isso, somos levados a concluir que a linguagem não pode ser "um meio para alcançarmos uma verdade que está fora" dela, como quer Frege... Isso nos leva a concluir também que o programa dos manuais de jornalísticos por "textos imparciais e objetivos" é, para dizer o mínimo, inalcançável. E se o conhecimento só pode ser expresso pela linguagem, então não é possível um "conhecimento seguro"!

\section{Pressuposição e argumentação}

O problema é que, no mundo jornalístico, tudo o que temos à disposição são os próprios relatos - e vimos que apenas com eles somos incapazes de emitir juízos conclusivos a propósito dos fatos. Desse modo, o editor (tanto quanto o leitor) não tem como avaliar a "veracidade" de um relato para publicálo: ele deve simplesmente acreditar nela. Trata-se de artigo de fé: supomos que o jornalista é apenas um "mediador" entre fatos e leitores, um observador neutro e privilegiado da realidade e que sua linguagem seja apenas um veículo transparente dessa realidade. A alternativa a essa fé é assumir que todo relato, mesmo aqueles compostos apenas por sentenças assertivas, é argumentação. O problema é que essa alternativa decreta logo de saída o fracasso do programa de tornar o jornalista um intermediário (objetivo) entre o fato e 0 leitor.

Ao falarmos da atitude geral dos autores dos relatos perante os eventos narrados, estávamos na verdade assinalando o fato de que suspeitávamos de um certo uso retórico daquelas "sentenças assertivas". Nossa "suspeita" nasce do fato de podermos conceber um relato diferente dos recolhidos nos portais tal que não entre em contradição direta e inequívoca com eles e, ainda assim, implique numa atitude distinta, esta, sim, em contradição com a expressa nos relatos de referência. Foi o caso do relato de segunda mão com o qual 
iniciamos este artigo. O que distingue esse relato hipotético dos demais? Simplesmente o fato de termos procurado, deliberadamente, "neutralizar" as sentenças quanto à afirmação de se os manifestantes atacaram ou não a polícia: nós não nos comprometemos com essa afirmação nem com sua negação. Seria igualmente possível construir o relato com base no compromisso oposto ao dos relatos, afirmando, por exemplo, a proposição "a polícia enfrentou os manifestantes" sem afirmar jamais a proposição "os manifestantes enfrentaram a polícia". E mesmo neste caso os eventos poderiam ser reconstruídos de modo similar: em qualquer caso, ainda poderíamos dizer que ocorreu um choque entre polícia e manifestantes em Hong Kong.

Nossa suposição é de que esses diferentes compromissos se originam em atitudes diversas previamente assumidas pelos observadores e se materializam em propósitos retóricos distintos. Se não existem observadores privilegiados $\mathrm{e}$, portanto, sujeitos descomprometidos, como questionamos anteriormente, então toda locução implica numa atitude perante o referente. Isto significa que as "representações individuais" de que fala Frege (FREGE, 1978, p. 64) não podem ser simplesmente um fenômeno marginal à linguagem através da qual pretendemos falar do mundo: elas devem estar muito mais próximas do cerne da linguagem em uso do que faz supor a reflexão do filósofo.

No caso que estamos analisando, esse compromisso se manifesta primeiramente sob a forma de escolhas: embora, como vimos, seja possível relatar $o$ evento sem marcar $o$ ataque dos manifestantes às forças policiais, todos os "observadores" escolheram afirmar precisamente isto. Essa escolha fica bastante evidente na comparação dos relatos sobre a quantidade de feridos: entre 41 feridos (a julgar pelo relato do UOL), o Terra preferiu ressaltar no seu relato um único policial, mencionando-o antes dos demais. Do mesmo modo, o Globo On-line preferiu descrever o conflito como o enfrentamento dos manifestantes com a polícia (e não o contrário), ressaltando os ativistas como 
agentes do conflito. Isto está igualmente evidente na chamada incluída na Figura 2Erro! Fonte de referência não encontrada., quando se escolheu marcar a ação da polícia como "revide", uma reação à ação dos manifestantes.

Tais escolhas marcam um enunciador comprometido com determinada versão dos eventos, que procura construir uma imagem da polícia local como mera vítima de manifestantes agressivos. Uma outra estratégia retórica utilizada para dar credibilidade a essa versão pode ser vista na sentença 3 da Tabela 1: trata-se de uma afirmação sobre o local onde ocorreu o incidente e, portanto, atende às convenções de "objetividade" do relato jornalístico (informar o que houve, quando e onde). No entanto, este enunciado assume como pressuposto um outro enunciado, que afirma que "o protesto foi violento". Novamente, a escolha de um "modo de apresentação" (para retornarmos à expressão fregeana) particular. Que os eventos devem ter sido violentos não resta dúvida, pelo menos a julgar pela quantidade de feridos. No entanto, o "observador" escolheu fazer uma afirmação endereçada aos manifestantes e não, por exemplo, à polícia, como, por exemplo, na sentença hipotética "a ação policial violenta ocorrida às portas do centro de convenções". Poderíamos dizer que esta última sentença seria plausível no contexto dos relatos, tanto pela quantidade de feridos entre os manifestantes quanto pelas "armas" utilizadas por eles (tambores e telefones celulares) para agredir a pacífica força policial munida de escudos, cassetetes elétricos, gás lacrimogêneo, gás pimenta e jatos de água. Como vemos, os próprios relatos possibilitam um compromisso distinto do efetivamente assumido: basta escolhermos uma atitude distinta...

Ao trazer para a cena do relato esse enunciador comprometido como sujeito de uma pressuposição, o jornalista do UOL se utiliza um artifício retórico simples e eficaz: assumir como dado, como fato, algo que precisa ser corroborado. Tal a força retórica da pressuposição: assumir como premissa o resultado de um raciocínio, sugerir que um argumento seja, na verdade, um fato. 
Um terceiro componente desse jogo retórico consiste na própria estrutura do gênero discursivo: trata-se de um relato jornalístico. Por um lado, as convenções do gênero assumem a forma de uma narrativa - e esperamos que narrativas se refiram a eventos; por outro lado, como se trata de gênero jornalístico - esperamos igualmente que tais eventos sejam "reais". Desse modo, as expectativas do leitor acabam por desempenhar um papel nesse drama retórico: o leitor tende a assumir tais expectativas como "pressupostos". $\mathrm{Na}$ presença de um "leitor desarmado" isso tende a produzir um efeito de convencimento, uma "aura de verdade" que investe os enunciados do relato.

\section{Protesto é guerra}

Até agora, discutimos o que chamamos o compromisso retórico dos relatos em elementos marginais à trama textual e o fizemos a partir do questionamento do referente dos seus enunciados. No entanto, ele também se manifesta no núcleo conceitual dos relatos, nas imagens que organizam 0 discurso. A abordagem desse novo problema requer, porém, uma rápida conceituação preliminar.

Alguns estudos nos domínios da Lingüística Cognitiva têm trazido a noção de metáfora para o centro das preocupações. Ao contrário da visão clássica do problema, a metáfora nessas pesquisas não é vista como uma "anomalia" no ramo principal da linguagem, como "uma espécie de agregado decorativo à linguagem comum, um dispositivo retórico para ser usado em certos momentos para obter certos efeitos" (SAEED, 2000 p. 346). Ao contrário, esses cognitivistas sustentam que a metáfora está no próprio ramo principal da linguagem, disseminada amplamente na própria linguagem quotidiana, embora admitam necessariamente a existência originária de conceitos não metafóricos. Elas são, contudo, o principal meio disponível para conhecermos o mundo e comunicarmos nossa experiência, permitindo-nos entender "um domínio da experiência em termos de outro" domínio (SAEED, 2000, p. 347). 
Ao longo da nossa histórica cognitiva (e lingüística), aprendemos, a partir da experiência sensória na interação com o mundo em que vivemos, alguns conceitos básicos, cristalizados sob a forma de "esquemas imagéticos" fundamentais e categorias elementares. É aplicável aqui o exemplo fornecido por Oliveira, numa longa citação: "a criança se move várias vezes em direção a certos alvos. Desses movimentos, emerge um esquema imagético sinestésico (uma memória de movimento) em que há um ponto de partida do movimento, um percurso e um ponto de chegada". O esquema imagético produzido por essa experiência fundamental "ancora o significado de nossas expressões lingüísticas sobre o espaço" (OLIVEIRA, 2003 p. 35). Como essas experiências fundamentais são comuns aos membros da espécie e da comunidade, os significados podem ser compartilhados e, portanto, comunicados sem ambigüidades fundamentais. Dessa concepção segue-se imediatamente que os significados lingüísticos não são arbitrários, mas motivados pelas experiências sensoriais e interações com o mundo.

À medida que somos submetidos a novas experiências e a conceitos e categorias cada vez menos apreensíveis diretamente por essas experiências, utilizamos os mecanismos metafóricos para estender os conceitos e significados apreendidos anteriormente para esses novos domínios de experiência. A metáfora é, portanto, "um processo cognitivo que permite mapearmos esquemas, apreendidos diretamente pelo nosso corpo, em domínios mais abstratos, cuja experimentação é indireta" (OLIVEIRA, 2003 p. 36). Assim é que, a partir do esquema básico de movimento, podemos apreender um domínio abstrato de experiência indireta como a "vida", que pode ser universalmente compreendida como uma viagem levando do nascimento à morte, desde as manifestações lingüísticas "elevadas" como a poesia (é irresistível aqui lembrarmos o célebre nel mezzo del camin di nostra vita) até às expressões quotidianas como "ela tem um bebê a caminho".

Naturalmente, a generalidade de tais conceitos torna sua abrangência universal, tornando possível utilizá-los para abordar desde o discurso das 
ciências matemáticas até o discurso político. Sabemos, se assumirmos tais premissas, que os esquemas imagéticos básicos devem ser universais porque derivam de experiências igualmente universais, pelo menos no escopo das experiências (universalmente) compartilhadas por uma comunidade (particular). Queremos, porém, determinar como pode se dar a utilização desses esquemas universais no contexto de experiências, vivências, conceitos e categorias que não são compartilhadas por todos os membros de uma comunidade, mas apenas por alguns. Em outras palavras, queremos determinar se esses pressupostos contribuem para a compreensão das ideologias, esses modelos conceituais compartilhados por alguns grupos sociais, mas não por outros.

De uma forma geral, o domínio conceitual da guerra e dos assuntos militares tende a ser apreendido em termos dos esquemas imagéticos de container e força. Expressões como "perímetro de segurança", "forçar a transposição" (de um obstáculo natural ou artificial), "fogo de barragem", "cerco", "assédio", “irrompimento das linhas" (inimigas), "bolsão defensivo", "envolvimento das forças" (inimigas ou amigas), "tropas de ocupação", "posto de fronteira", etc. são de utilização corriqueira tanto no jargão profissional e especializado, como em relatos jornalísticos a propósito da guerra. A aparente universalidade dessas metáforas provavelmente decorre da aparente universalidade (e permanência) da experiência bélica. Se nos é permitida uma pequena especulação paleolingüística, elas possivelmente nasceram com a própria linguagem, no momento em que algum dos nossos ancestrais antropóides decidiu que era mais simples recorrer a paus e pedras contra 0 grupo vizinho que procurar novos territórios de coleta e caça ou fabricar suas próprias ferramentas. Pelo menos essa é uma das narrativas possíveis contadas por crânios esmagados e perfurados encontrados em inúmeros sítios palenteológicos.

Esse esquema imagético aplicado às relações (conflituosas) entre grupos sociais é igualmente aplicado às relações (possivelmente conflituosas) dentro do mesmo grupo social. É também esperada a utilização das metáforas do 
domínio conceitual estritamente militar quando a "questão social" se torna "caso de polícia". O inventário exibido na Tabela 2, composto por $40 \%$ do corpus (mais especificamente daquela parcela do relato diretamente relacionada ao incidente envolvendo a polícia e os manifestantes), é ilustrativo da utilização desses esquemas conceituais aplicados indiscriminadamente a conflitos militares e sociais.

\begin{tabular}{|l|l|}
\hline 1 & Manifestantes rompem cerco perto do local da reunião da OMC. \\
\hline 2 & $\begin{array}{l}\text { Um grupo de manifestantes conseguiu romper hoje o cerco policial em torno do } \\
\text { centro de convenções de Hong Kong. }\end{array}$ \\
\hline 3 & $\begin{array}{l}\text { Os ativistas se uniram para atacar as barreiras policiais que mantêm vazias as } \\
\text { ruas nas proximidades do edifício. }\end{array}$ \\
\hline 4 & $\begin{array}{l}\text { Eles obrigaram dezenas de agentes a se dispersarem protegidos com escudos e } \\
\text { armados com cassetetes elétricos. }\end{array}$ \\
\hline 5 & $\begin{array}{l}\text { A proteção dos acessos ao edifício está sendo reforçada com vários agentes com } \\
\text { máscaras antigás, escudos antidistúrbios e cassetetes elétricos. }\end{array}$ \\
\hline 6 & $\begin{array}{l}\text { Mais de } 900 \text { manifestantes foram detidos hoje pela Polícia de Hong Kong após os } \\
\text { violentos protestos ocorridos às portas do centro de convenções onde ocorre a } \\
\text { reunião da Organização Mundial do Comércio (OMC). }\end{array}$ \\
\hline 7 & Manifestantes entram em choque com a polícia para invadir reunião. \\
\hline 8 & $\begin{array}{l}\text { Forças de segurança lutavam para evitar a invasão do centro de convenções por } \\
\text { manifestantes recorrendo a jatos de água e sprays de gás de pimenta. }\end{array}$ \\
\hline 9 & $\begin{array}{l}\text { A polícia de Hong Kong deteve mais de } 900 \text { pessoas para controlar os protestos } \\
\text { nos arredores do centro de convenções. }\end{array}$ \\
\hline 10 & $\begin{array}{l}\text { Os detidos, mantidos sob custódia policial num perímetro guardado, na rua } \\
\text { mesmo, serão levados para uma prisão no centro da cidade. }\end{array}$ \\
\hline
\end{tabular}

Tabela 2: Inventário de imagens utilizadas no corpus.

Esse inventário das metáforas conceituais ocorrentes nos relatos, por si só, nada nos informa a propósito do problema que queremos encontrar, isto é, sua utilização ideológica. Afinal, a expressão "invadir (e ocupar) a fábrica" é utilizada tanto pelos operários revoltados quanto pela polícia convocada para repelir a invasão... No entanto, dois lados se confrontam na guerra: amigos e inimigos. No caso da "questão social", é de se esperar que a identificação de um dos lados como "amigo" e do outro como "inimigo" seja uma atitude 
ideológica. Assim, procuramos associar as metáforas de container e força daquele inventário aos dois lados em conflito - manifestantes e policiais - nos vários relatos jornalísticos recolhidos, na busca de regularidade na sua utilização. O resultado é mostrado na Tabela 3.

\begin{tabular}{|c|c|c|}
\hline Manifestantes & Polícia & Fonte \\
\hline \multicolumn{3}{|l|}{$\begin{array}{l}\text { Manifestantes rompem cerco perto } \\
\text { do local da reunião da OMC }\end{array}$} \\
\hline $\begin{array}{l}\text { Um grupo de manifestantes } \\
\text { conseguiu romper }\end{array}$ & $\begin{array}{l}\text { o cerco policial em torno do centro } \\
\text { de convenções de Hong Kong }\end{array}$ & Terra \\
\hline \multirow[t]{4}{*}{ Os ativistas se uniram para atacar } & $\begin{array}{l}\text { as barreiras policiais que mantêm } \\
\text { vazias as ruas }\end{array}$ & Terra \\
\hline & protegidos com escudos & Terra \\
\hline & $\begin{array}{l}\text { A proteção dos acessos ao edifício } \\
\text { está sendo reforçada com vários } \\
\text { agentes }\end{array}$ & Terra \\
\hline & $\begin{array}{l}\text { Mais de } 900 \text { manifestantes foram } \\
\text { detidos }\end{array}$ & UOL \\
\hline $\begin{array}{l}\text { Manifestantes entram em choque } \\
\text { com a polícia }\end{array}$ & & Globo \\
\hline para invadir reunião & & Globo \\
\hline \multirow[t]{3}{*}{$\begin{array}{l}\text { a invasão do centro de convenções } \\
\text { por manifestantes }\end{array}$} & & Globo \\
\hline & $\begin{array}{l}\text { A polícia de Hong Kong deteve } \\
\text { mais de } 900 \text { pessoas }\end{array}$ & Globo \\
\hline & $\begin{array}{l}\text { Os detidos, mantidos sob custódia } \\
\text { policial num perímetro guardado }\end{array}$ & Globo \\
\hline
\end{tabular}

Tabela 3: Ocorrência de metáforas envolvendo os esquemas de container e força.

De um modo geral, o esquema da "força" está direta e unicamente associado aos manifestantes, através dos verbos "romper", "atacar", "entrar" (em choque) e "invadir", enquanto que o esquema do container está associado à polícia, através dos vocábulos "cerco", "barreira", "proteção", "escudo" e "perímetro". Interessante também é a associação do esquema secundário da contra-força à polícia, através do verbo "deter". Portanto, de uma forma geral 
as metáforas são cuidadosamente utilizadas para justificar a proposição argumentativa - comum a todos os relatos - tão bem cristalizada na legenda do Globo: "protesto (violento) e revide".

É importante ressaltar que a justificativa da luta desempenha hoje um importante papel na ideologia da guerra. Mesmo Hitler procurou justificar a invasão da então Tchecoslováquia como um ato de autodefesa. Afinal, nossos poetas tendem a não mais glorificar os "saqueadores de cidades" outrora celebrados por Homero: para nós, uma guerra "justa" é uma "guerra defensiva", uma guerra travada em defesa do "nosso perímetro" ou um "revide" à agressão. Avaliando a Tabela 3 sob essa luz, notamos que a distribuição das metáforas conceituais não é aleatória! Os "caras bons" dentro do perímetro devem ser protegidos dos "caras maus" que querem invadi-lo pelos heróicos soldados da pátria. Protesto e revide... A simples realização de uma manifestação política ou social é encarada como uma declaração de guerra e é o bastante para a mobilização das forças patrióticas em defesa do solo sagrado. A identificação com um dos lados em conflito é simples e direta, desprovida de subterfúgios. Os relatos, portanto, estão comprometidos com um dos lados em conflito e isso se manifesta também na distribuição das metáforas conceituais encontradas nos relatos selecionados.

\section{Referências bibliográficas}

FREGE, G. Lógica e filosofia da linguagem. São Paulo: Cultrix, 1978.

KRESS, G.; VAN LEEUWEN, T. Reading images: the grammar of visual design. London: Routledge, 1996.

OLIVEIRA, R. P. Semântica. In: MUSSALIM, F.; BENTES, A. C. (Orgs.).

Introdução à lingüística: domínios e fronteiras. 3. ed. São Paulo: Cortez, 2003. v.2, p. 17-46.

SAEED, J. I. Semantics. London: Blackwell, 1997. 


\begin{tabular}{|l|l|l|l|l|l|l|}
\hline InterteXto & Uberaba & UFTM & v. 1 & p. 209-226 & 2008 - jan. / jun. & ISSN 1981-0601 \\
\hline
\end{tabular}

FOLHA DE SÃO PAULO. Manual geral da redação. São Paulo: Folha de São Paulo, 2001.

GLOBO. Rascunho da declaração da OMC é modesto e decepcionante, diz Brasil. Disponível em: < http://oglobo.globo.com/especiais/exterior/189682490.asp>. Acesso em: 17 dezembro 2005.

O ESTADO DE SÃO PAULO. Manual de redação e estilo. Organizado por E. Martins. São Paulo: Câmara Brasileira do Livro, 1990.

TERRA. Manifestantes rompem cerco perto do local da reunião da OMC.

Disponível em: < http://br.invertia.com/noticias/noticia.aspx?idNoticia= 200512171145_AEB_28899787>. Acesso em: 17 dezembro 2005. UOL. Mais de 900 detidos e 41 feridos após manifestação anti-OMC. Disponível em: < http://noticias.uol.com.br/ultnot/2005/12/17/ult1767u56993. jhtm>. Acesso em: 17 dezembro 2005. 